\title{
Decoding spatial formatting: the analysis of the world order through educational atlases
}

\author{
Sofia Gavrilova ${ }^{\mathrm{a}, *}$, Jana Moser ${ }^{\text {a }}$, Philipp Meyer ${ }^{\text {a, }}$, Sebastian Lentz ${ }^{\text {a }}$ \\ ${ }^{a}$ Leibniz Institute for Regional Geography, s_gavrilova@leibniz-ifl.de, j_moser@leibniz-ifl.de, p_meyer@leibniz-ifl.de, \\ s_lentz@leibniz-ifl.de \\ * Corresponding author
}

Keywords: educational maps, world atlases, spatial formatting

\begin{abstract}
:
The proposed abstract is presenting the ongoing project, which explores the ways maps (especially maps in school education) communicating and shape ideas and imaginations about space they represent. In our project, maps are seen as mediums of knowledge and perception of space, which are prominent in a particular time and society. The project is part of a bigger ongoing research initiative, which explores the variety of spatial formatting in social action, revealing its rhetorical construction, methods of state production and implementation, and ways those formats have been communicated to the wider public. The proposed presentation focuses on the part dedicated to the production and communicating of spatial formats through educational maps and school atlases, the methods of depicting those formats and the background of production of such material.
\end{abstract}

The project has two main aims. The first one focuses on the map languages and the visualization techniques, and the second one is to analyse the presence or absence of particular forms of globalization on the maps and in world atlases, produced in various case study countries. The project focuses on educational world atlases, produced from XIX century until the present day in France, China, Russia, US and Germany.

Methodologically 'decoding' spatial concepts and visual techniques they are communicated consist of two steps. Firstly, we focus on the overarching atlas contents and structure, visual variables on particular maps, colours, borderlines and other important elements of the maps (all together more than twelve various parameter). This analysis has been formalized in the table analysis, which allows us to 'code' the particular maps and atlases. In other words, the project formalizes such spatial concepts as 'nation states', 'nation state regime with colonial extensions', 'networks' and others through the coding of the atlas contents and particularly maps. Secondly, we focus on the social and cultural context of the atlas production, as well as historical events which could influence the representation of such spatial formats. These two strands of analysis allowed us to (a) create a mixed method approach of quantitative and qualitative analysis of world atlases (Cherrier et al. 2019) which could also be embedded in other projects, (b) to understand the most significant elements of the maps and their combination, which stand for a spatial concept and (c) analyse particular spatial formats as they are laid down in the educational cartographic material shaping a society.

The preliminary findings on this research project allows us to approach the spatial format of the "nation state regime with colonial extensions', which has emerged in the XIX century when the classical Empires starts to be transformed to the nation states of the XX century. According to Marung/Middel (2019) these transitions have formed the way spaces have been perceived and communicated, especially in the imperial states that have been 'nationalized and partially democratized'. The 'nation state with colonial extension' can be seen as transformation stage from Empires to nation states, which started among others because of the rapid development of means of transportation and communication. Such spatial units have been depicted by several signifiers that we are looking for and are able to decode from the maps, atlas structure as well as additional texts. First of all, in terms of contents, these maps are mixing up the presence of nation state borderlines, and of colonies. Secondly, quite often, the borders themselves are presented in several types (borders between nation states, borders between colonies etc.). In terms of visual variables, these countries usually have specific colour schemes, which allow us to relate particular colonies with nation states. Thirdly, quite often we notice the presence of transportation routes on world maps. To contextualise and interpret such findings we rely on additional archival material, interviews with educational map producers as well as governmental instructions concerning educational content.

The proposed presentation is addressing all the three main points above: it presents the developed methodology of the atlases analysis and discusses the ways and limits of its implementation; it unpacks the notion of the 'spatial formats' 
and shows how it can be decoded in a map, or a combination of maps and finally it discusses the reasons behind the production of particular maps and atlases and the reasons of presence or absence of a spatial format in a particular map.

\section{References (optional)}

Cherrier, Pierre; Moser, Jana; Lentz, Sebastian; Pflug, Laura (2019): Raumformate und Kartensprachen erkennen. Vorschlag einer Methodik zur Analyse von Karten und (Schul)Atlanten als Vermittler von Weltbildern unter Globalisierungsprozessen. Leipzig: Leipziger Universitätsverlag (Working paper series des SFB 1199 an der Universität Leipzig, 19). https://research.uni-leipzig.de/ sfb1199/wp-content/uploads/2019/04/WP19_Moser-etal_web_190430.pdf

Marung, Steffi; Middell, Matthias (2019): The Respatialization of the World as one of the Driving Dialectics under the Global Condition. In: Steffi Marung und Matthias Middell (Hg.): Spatial formats under the global condition. Berlin, Boston: Walter de Gruyter (Dialectics of the global), p. 1-11. 